\title{
CONVENIENT APPROACH FOR THE SYNTHESIS OF \\ 2-AMINOBENZOTHIAZOLOMETHYL NAPHTHOLS USING TRISODIUM CITRATE DIHYDRATE AS GREEN CATALYST UNDER MICROWAVE IRRADIATIONS
}

\author{
NAVEEN SINGH CHAUHAN ${ }^{\mathrm{a}}$ AND JAGGI LAL ${ }^{\mathrm{b} 1}$
}

${ }^{\mathrm{ab}}$ Department of Chemistry, NIMS Institute of Engineering and Technology, NIMS University, Jaipur, Rajasthan, India

\begin{abstract}
The present research paper deals with the development a simple, highly efficient, straightforward, multicomponent one-pot scalable approach for the synthesis of a series of biologically active 2-aminobenzothiazolomethyl naphthols. The method is based on an easily available, cheap and environmentally benign trisodium citrate dihydrate (TSCD) catalyst using microwave irradiations reactions of $\beta$-naphthol, 2-aminobenzothiazole and aromatic aldehydes in water. Metal-free synthesis, good to excellent yields of the products, short reaction time, operational simplicity, eco-friendliness and mild reaction conditions are some of the important features of this protocol. The method is demonstrated on multi gram level. Easy workup procedure and most importantly environmentally benign are the most outstanding advantages of this procedure.
\end{abstract}

KEYWORDS: Trisodium Citrate Dihydrate, Microwave Irradiations, Green and Scalable Synthesis, 2-Aminobenzothiazolomethyl Naphthols

As per the stringent environment concers, now these days, the use of environmentally benign materials and solvents are highly demanding in fine and pharmaceutical chemical industries. In seacrh of environment friendly, sustainable resources and catalyst, aqueous ethanol and trisodium citrate dihydrate (TSCD) may be an attractive candidates in the search for such type of non-toxic, cheap, easily available environmentally benign materials for the synthesis of 2-aminobenzothiazolomethyl naphthols. The 2-aminobenzothiazolomethyl naphthols is a highly potential biologically active compound and has various biological activities such as antitumor (Hutchinson et al., 2001), antiviral (Paget et al., 1969), antifungal (Singh et al., 2006), antibacterial (Palkar et al., 2010), antiinflammatory (El-Shorbagi et al., 1989), topoisomerase II inhibitory (Choi et al., 2006), as well as anticonvulsant (Amnerkar and Bhusari, 2010). 2-Aminobenzothiazoles are highly reactive compounds and used as reactants or reaction intermediates to synthesize a wide variety of biologically active fused heterocyclic compounds and in other organic transformations (Erian, 1993). In recent years, various procedures have been exist in literature for the synthesis of 2-aminobenzothiazolomethyl naphthol derivatives by adopting one-pot multi-component reactions (Hulme et al., 2009) (Jiang et al., 2010) (Dömling et al., 2012), like Agar (Moradi et al., 2015), Citric acid (Lashkari et al., 2016), $\mathrm{Fe}_{3} \mathrm{O}_{4} @ \mathrm{SiO}_{2}-\mathrm{ZrCl}_{2}-$
MNPs (Kamali and Shirini, 2018), Fumaric acid (Maghsoodlou et al., 2016), Graphite-supported $\left(\mathrm{HClO}_{4}{ }^{-}\right.$ C) (Lei et al., 2013), Grindstone (Mohan et al., 2015), Heteropoly acids (Javanshir et al., 2014), Ionic liquids (Yu and Guo, 2011), L-valine (Lal et al., 2020), Magnetic nanocatalyst (Lati et al., 2018), Maltose (Adrom et al., 2015), Microwave irradiations (Niralwad et al., 2011), Ionic liquid (Shaterian and Hosseinian, 2014), $\mathrm{NaHSO}_{4} \cdot \mathrm{H}_{2} \mathrm{O}$ (Shaterian and Mohammadnia, 2013), NBS (Hosseinian and Shaterian, 2012), Phosphate Fertilizers (Li et al., 2013), Sodium dodecyl sulfate (Zimou et al., 2019), Sphalerite (Lal, 2015), Trichloroisocyanuric acid (Kumar et al., 2010), Wells-Dawson heteropoly acid (Yang L., 2012), Zinc oxide micelles (Ohanian et al., 2009), $\gamma$-Aminobutyric acid and collagen peptides biocatalyst (Mou et al., 2017) and heterogenous phosphate catalysts (Fardpour et al., 2018).These reported protocols produce good yields of the products in many instances (Shaabani et al., 2007). However, some of the synthetic protocols undergo with certain limitations such as use of very expensive catalysts, solvents, large amount of catalyst, low yields of products, long reaction times, tedious procedures for preparations of catalysts and tedious workup conditions. Hence, the development of simple, efficient and environmentally benign protocol using non-toxic recyclable cheap catalyst under water for the synthesis of 2-aminobenzothiazolomethyl naphthols is still desirable and demanding in present days. 
To the best of our knowledge, few reports are available in literature on the use of trisodium citrate dihydratealone as catalyst in synthetic organic chemistry (Brahmachari and Nurjamal, 2019) (Brahmachari and Banerjee, 2016) (Brahmachari and Nurjamal, 2016). In continuation of our research interest and a part of ongoing research programme (Lal et al., 2012 \& 2016), in the development of green and sustainable protocols for onepot multicomponent synthesis we here in wish to report a new methodology for the synthesis of 2aminobenzothiazolomethyl naphthols using trisodium citrate dehydrate as green and non-toxic catalyst in water using microwave conditions.

\section{EXPERIMENTAL}

The reagents used during the study were obtained commercially from Merck, Qualikems, Rankem, Spectrochem and TCI and used as received. All the synthesized derivatives were identified by comparing their melting points and spectral data with those of the authentic samples reported in literature. Melting point of all the synthesized compounds was determined on electrothermal melting point apparatus in an open capillary tube and report uncorrected. IR spectra of the synthesized compounds were recorded on A2 technology in terms of frequency of absorption $\left(\mathrm{cm}^{-1}\right)$. Mass spectra were recorded on Egilent ION TRAP 6310 mass spectrometer. ${ }^{1} \mathrm{H}$ NMR spectra were recorded on BRUKER AVANCE II 400 NMR Spectrometer using TMS as an internal standard at room temperature in DMSO $\mathrm{d}_{6}$ solvent.

\section{Synthesis of 2-aminobenzothiazolomethyl naphthols}

$\beta$-naphthol 1 (0.69 mmol, 1 equiv.), substituted aromatic aldehydes 2 (0.69 mmol, 1.2 equiv.), 2aminobenzothiazole 3 (0.69 mmol, 1.2 equiv.) and trisodium citrate dihydrate catalyst $(10 \mathrm{~mol} \%)$ in $2 \mathrm{~mL}$ water transferred to a $10 \mathrm{~mL}$ oven dried reaction vial and the reaction vial is irradiated using microwave irradiations for about 9-10 $\mathrm{min}$. The reaction was monitored by TLC using ethyl acetate/hexane (30:70) as eluent. After completion, the reaction mixture was cooled to room temperature and stirred the contents after adding ethanol. The residual product was recrystallized from hot ethanol to give the pure product4a-o (Scheme 1).

\section{Gram scaled-up synthesis of 2-aminobenzothiazolo methyl naphthols}

$\beta$-naphthol 1 (1 equiv.), substituted aromatic aldehydes 2 (1.2 equiv.), 2-aminobenzothiazole 3 (1.2 equiv.) and trisodium citrate dihydrate catalyst (10 mol\%) in $10 \mathrm{~mL}$ water transferred to a $50 \mathrm{~mL}$ oven dried round bottom flask and the reaction flask is irradiated withmicrowave irradiations for about $12 \mathrm{~min}$. The reaction was monitored by TLC using ethyl acetate/hexane (30:70) as eluent. After completion, the reaction mixture was cooled to room temperature and stirred the contents after adding ethanol. The residual product was recrystallized from hot ethanol to afford the pure product $4 \mathrm{a}($ Scheme 2$)$.

\section{Competitive Experiment}

A $10 \mathrm{~mL}$ reaction vial was charged with $\beta$ naphthol 1(0.69 mmol), 3-methoxybenzaldehyde 2 (0.69 mmol), 3-nitrobenzaldehyde 2 (0.69 mmol), 2aminobenzothiazole $3(0.69 \mathrm{mmol})$, and trisodium citrate dihydrate catalyst $(10 \mathrm{~mol} \%)$ and $5 \mathrm{~mL}$ water and the reaction vial is irradiated with microwave irradiations for $10 \mathrm{~min}$. The reaction was monitored by TLC using ethyl acetate/hexane (30:70). After completion, the reaction mixture was cooled to room temperature and stirred the contents after adding ethanol. The residual product was recrystallized from hot ethanol to give the products $4 \mathrm{~b}$ and $5 \mathrm{c}$ in $64 \%$ and $21 \%$ yields respectively, (Scheme 3 ).

\section{Characterization Data of Some Selected Compounds}

\section{1-(Benzo[d]thiazol-2-ylamino) (phenyl) methyl) naphthalene-2-ol (4a):}

Reaction was carried out according to the procedure with $\beta$-naphthol $(0.69 \mathrm{mmol})$, benzaldehyde $(0.83 \mathrm{mmol})$ and 2 -aminobenzothiazole $(0.83 \mathrm{mmol})$ to give compound $4 \mathrm{a}$. White solid, IR $\lambda \max , \mathrm{cm}^{-1}$ : 3501 , 3386, 1594, 1546, 1512, 1451; ${ }^{1} \mathrm{H}$ NMR (DMSO-d 6 , 400 $\mathrm{MHz}): \delta=6.95-7.92(16 \mathrm{H}, \mathrm{m}, 15 \mathrm{H}$ arom, $1 \mathrm{H}-\mathrm{CH}), 8.64$ $(1 \mathrm{H}, \mathrm{s}, \mathrm{NH}), 10.12(1 \mathrm{H}, \mathrm{s}, \mathrm{OH}) ;{ }^{13} \mathrm{C}$ NMR (DMSO-d ${ }_{6}$, $100 \mathrm{MHz}): \delta=53.34,117.02,116.52,117.80,121.47$, $121.82,121.25,122.57,124.22,125.03,126.81,127.31$, 129.57, 128.31, 131.57, 131.13, 141.24, 152.94, 151.17, 167.31; EIMS m/z: Calcd for $\mathrm{C}_{24} \mathrm{H}_{18} \mathrm{~N}_{2} \mathrm{OS} 382.4810$, found $383.4813[\mathrm{M}+1]^{+}$.

\section{1-(Benzo[d]thiazol-2-ylamino)(3-nitrophenyl) naphthalene-2-ol (4c)}

Reaction was carried out according to the procedure with $\beta$-naphthol $(0.69 \mathrm{mmol}), 3$-nitrobenzaldehyde $(0.83 \mathrm{mmol})$ and 2-aminobenzothiazole ( $0.83 \mathrm{mmol})$ to give compound $4 \mathrm{c}$. White powdered solid, IR $\left(\lambda \max , \mathrm{cm}^{-1}\right): 3335,1627,1597,1531,1452 ;{ }^{1} \mathrm{H}$ NMR $\left(\mathrm{DMSO}_{6}, 400 \mathrm{MHz}\right) \delta=7.05-7.88(15 \mathrm{H}, \mathrm{m}, 14 \mathrm{H}$ arom, $1 \mathrm{H}-\mathrm{CH}), 8.90(\mathrm{~s}, 1 \mathrm{H}, \mathrm{NH}), 10.12(\mathrm{~s}, 1 \mathrm{H}, \mathrm{OH}) ;{ }^{13} \mathrm{C} \mathrm{NMR}$ $\left(\mathrm{DMSO}_{6}, 100 \mathrm{MHz}\right): \delta=54.38, \quad 116.12,118.72$, $119.41,119.62$, 119.82, 121.84, 121.91, 123.28, 126.43, 
$126.99,129.41,129.55,130.27,131.23,133.12,146.14$ 152.48, 154.06, 167.22; Calcd for $\mathrm{C}_{24} \mathrm{H}_{17} \mathrm{~N}_{3} \mathrm{O}_{3} \mathrm{~S}$ 427.4780, found $428.4781[\mathrm{M}+1]^{+}$.

\section{1-(Benzo[d]thiazol-2-ylamino)(2-hydroxyphenyl) methyl) naphthalene-2-ol (4e)}

Reaction was carried out according to the procedure with $\beta$-naphthol (0.69 mmol), 2-hydroxybenzaldehyde $(0.83 \mathrm{mmol})$ and 2-aminobenzothiazole (0.83 mmol) to give compound 4e.Off white solid, IR $\left(\lambda \max , \mathrm{cm}^{-1}\right): 3612,3302,2943,1628,1506,1284,961-$ $811 \mathrm{~cm}^{-1} ;{ }^{1} \mathrm{H}$ NMR $\left(\operatorname{DMSOd}_{6}, 400 \mathrm{MHz}\right): \delta=6.68-7.92$ $(15 \mathrm{H}, \mathrm{m}, 14 \mathrm{H}$ arom, $1 \mathrm{H}-\mathrm{CH}), 8.67(1 \mathrm{H}, \mathrm{s}, \mathrm{NH}), 10.02$ $(1 \mathrm{H}, \mathrm{s}, \mathrm{OH}) ;{ }^{13} \mathrm{C}$ NMR (DMSO-d $\left.6,100 \mathrm{MHz}\right): \delta=\mathbf{5 1 . 8 4}$, $116.73,117.75,118.81,119.43,120.62,121.13,121.22$, $122.51,125.52,126.32,128.21,128.96,129.82,128.53$, 129.26, 132.14, 136.35, 150.83, 152.63, 154.46, 166.52; EIMS m/z: Calcd for $\mathrm{C}_{24} \mathrm{H}_{18} \mathrm{~N}_{2} \mathrm{O}_{2} \mathrm{~S} 398.4800$, found $399.4802[\mathrm{M}+1]^{+}$.

\section{1-(Benzo[d]thiazol-2-ylamino)(p-tolyl)methyl)methyl) naphthalene-2-ol (4f):}

Reaction was carried out according to the procedure with $\beta$-naphthol $(0.69 \mathrm{mmol})$, 4-methylbenzaldehyde $(0.83 \mathrm{mmol})$ and 2-aminobenzothiazole ( $0.83 \mathrm{mmol})$ to give compound $4 \mathrm{f}$. White solid, IR ( $\lambda \max$, $\left.\mathrm{cm}^{-1}\right)$ : 3609, 3007, 2922, 1625, 1510, $1267 \mathrm{~cm}^{-1} ;{ }^{1} \mathrm{H}$ NMR (DMSO-d $6,400 \mathrm{MHz}$ ): $\delta=2.23\left(3 \mathrm{H}, \mathrm{s}, \mathrm{CH}_{3}\right), 6.95-7.39$ $(15 \mathrm{H}, \mathrm{m}, 14 \mathrm{H}$ arom and $1 \mathrm{H}-\mathrm{CH}), 8.66(1 \mathrm{H}, \mathrm{s}, \mathrm{NH}), 10.14$ $(1 \mathrm{H}, \mathrm{s}, \mathrm{OH}) ;{ }^{13} \mathrm{C}$ NMR (DMSO-d $\left.6,100 \mathrm{MHz}\right): \delta=20.60$, $53.33,118.00,118.66,118.92,120.51,120.85,122.27$, $125.26,126.03,128.34,128.50,128.60,129.22,130.55$, 132.13, 135.17, 139.13, 151.97, 153.20, 166.39; EIMS $\mathrm{m} / \mathrm{z}$ : Calcd for $\mathrm{C}_{25} \mathrm{H}_{20} \mathrm{~N}_{2} \mathrm{OS} 396.5080$, found 397.5082 $[\mathrm{M}+1]^{+}$.

\section{1-(Benzo[d]thiazol-2-ylamino)(4-chlorophenyl) naphthalene-2-ol (4g)}

Reaction was carried out according to the procedure with $\beta$-naphthol $(0.69 \mathrm{mmol})$, 4-chlorobenzaldehyde $(0.83 \mathrm{mmol})$ and 2-aminobenzothiazole (0.83 mmol) to give compound $4 \mathrm{~g}$. White powder, IR $\left(\lambda \max , \mathrm{cm}^{-1}\right): 3602,3304,1627,1267,1122 \mathrm{~cm}^{-1} ;{ }^{1} \mathrm{H}$ NMR (DMSO-d $6,400 \mathrm{MHz}): \delta=6.67-7.78(15 \mathrm{H}, \mathrm{m}, 14 \mathrm{H}$ arom, $1 \mathrm{H}-\mathrm{CH}), 8.57(1 \mathrm{H}, \mathrm{s}, \mathrm{NH}) ;{ }^{13} \mathrm{C}$ NMR (DMSO-d $\mathrm{d}_{6}$, $100 \mathrm{MHz}): \delta=53.48,117.71,118.13,118.96,120.95$, $121.12,122.43,122.47,125.81,126.82,127.30,127.78$, 128.22, 129.54, 130.32, 134.52, 138.16, 151.61, 153.28, 166.89; EIMS m/z: Calcd for EIMS m/z: Calcd for $\mathrm{C}_{24} \mathrm{H}_{17} \mathrm{ClN}_{2} \mathrm{OS} 416.9220$, found $417.9221[\mathrm{M}+1]^{+}$.

\section{1-(Benzo[d]thiazol-2-ylamino)(4-hydroxy-3- methoxyphenyl) methyl) naphthalene-2-ol (4i)}

Reaction was carried out according to the procedure with $\beta$-naphthol $(0.69 \mathrm{mmol})$, 3-hydroxy-3methoxy benzaldehyde $(0.83 \mathrm{mmol})$ and 2aminobenzothiazole $(0.83 \mathrm{mmol})$ to give compound 4i.Off white solid, IR $\left(\lambda \max , \mathrm{cm}^{-1}\right)$ : 3512, 3380, 1597, 1541, 1517, $1448 \mathrm{~cm}^{-1} ;{ }^{1} \mathrm{H}$ NMR (DMSO-d 6 , $400 \mathrm{MHz}$ ): $\delta=3.58\left(3 \mathrm{H}, \mathrm{s}, \mathrm{OCH}_{3}\right) 6.67-7.91(14 \mathrm{H}, \mathrm{m}, 13 \mathrm{H}$ arom, $\left.{ }^{1} \mathrm{H}-\mathrm{CH}\right), 8.81(1 \mathrm{H}, \mathrm{s}, \mathrm{NH}), 10.13(1 \mathrm{H}, \mathrm{s}, \mathrm{OH}) ;{ }^{13} \mathrm{C} \mathrm{NMR}$ $\left(\right.$ DMSO-d $\left._{6}, 100 \mathrm{MHz}\right)$ : d $=54.36,56.55,116.11,118.74$, $119.42,119.60,119.83,121.81,121.94,123.26,126.41$, $126.97,129.42,129.53,130.26,131.21,133.11,133.65$, 146.13, 148.23, 152.46, 154.04, 167.21; EIMS m/z: Calcd for $\mathrm{C}_{25} \mathrm{H}_{20} \mathrm{~N}_{2} \mathrm{O}_{3} \mathrm{~S} 428.5050$, found $429.5052[\mathrm{M}+1]^{+}$.

\section{1-(Benzo[d]thiazol-2-ylamino)(4-methoxyphenyl) methyl)naphthalene-2-ol (4I)}

Reaction was carried out according to the procedure with $\beta$-naphthol (0.69 mmol), 3-methoxybenzaldehyde $(0.83 \mathrm{mmol})$ and 2-aminobenzothiazole ( $0.83 \mathrm{mmol})$ to give compound $4 \mathrm{l}$. Off white solid, IR $\left(\lambda \max , \mathrm{cm}^{-1}\right): 3612,3513,3014,2920,1623,1509,1276$; ${ }^{1} \mathrm{H}$ NMR (DMSO-d $\left.6,400 \mathrm{MHz}\right): \delta=3.67\left(3 \mathrm{H}, \mathrm{s}, \mathrm{OCH}_{3}\right)$, 6.68-7.96 (15H, m, 14H arom, 1H-CH), $8.53(1 \mathrm{H}, \mathrm{s}, \mathrm{NH})$, $10.52(1 \mathrm{H}, \mathrm{s}, \mathrm{OH}) ;{ }^{13} \mathrm{C}$ NMR (DMSO-d $\left.6,100 \mathrm{MHz}\right): \delta=$ $54.83,67.45,118.14,119.01,119.13,120.56,122.51$, $125.51,126.24,127.40,128.45,128.76,129.36,130.21$, 132.14, 133.54, 132.10, 142.23, 151.66, 153.36, 166.82; EIMS m/z: Calcd for $\mathrm{C}_{25} \mathrm{H}_{20} \mathrm{~N}_{2} \mathrm{O}_{2} \mathrm{~S}$ 412.5070, found $413.5069[\mathrm{M}+1]^{+}$.

\section{1-(Benzo[d]thiazol-2-ylamino)(4-nitrophenyl)methyl) naphthalene-2-ol (40)}

Reaction was carried out according to the procedure with $\beta$-naphthol $(0.69 \mathrm{mmol})$, 4-nitrobenzaldehyde $(0.83 \mathrm{mmol})$ and 2-aminobenzothiazole $(0.83 \mathrm{mmol})$ to give compound 4o. White powdered solid, IR ( $\left.\lambda \max , \mathrm{cm}^{-1}\right): 3503,3346,2930,1628,1512$, 1265, 961-814 $\mathrm{cm}^{-1} ;{ }^{1} \mathrm{H}$ NMR (DMSO-d $6,400 \mathrm{MHz}$ ): $\delta=$ 6.72-7.31 (15H, m, 14H arom, 1H-CH), $8.64(1 \mathrm{H}, \mathrm{s}, \mathrm{NH})$, $10.02(1 \mathrm{H}, \mathrm{s}, \mathrm{OH}) ;{ }^{13} \mathrm{C}$ NMR (DMSO-d $\left.6,100 \mathrm{MHz}\right): \delta=$ 53.41, 117.83, 118.32, 118.56, 119.57, 120.44, 122.51, 123.26, 125.22, 127.32, 125.34, 126.62, 127.34, 128.55, 128.97, 129.91, 145.96, 150.66, 153.36, 166.68; Calcd for $\mathrm{C}_{24} \mathrm{H}_{17} \mathrm{~N}_{3} \mathrm{O}_{3} \mathrm{~S} 427.4780$, found $428.4782[\mathrm{M}+1]^{+}$.

The spectral data are in good agreement with the literature data. 


\section{RESULTS AND DISCUSSION}

To pursue our interest in the development of green protocol for the synthesis of 2-aminobenzothiazolomethyl naphthols, we instigate the study of the reaction based on a trial reaction between $\beta$-naphthol ( 1,1 equiv.), benzaldehyde (2, 1.2 equiv.) and 2-aminobenzothiazole (3, 1.2 equiv.) in the absence andpresence of trisodium citrate dihydrate catalysts under microwave irradiations in water, Table 2 , with varying amount of catalyst loading and solvents. The best results were obtained in the presence of $10 \mathrm{~mol} \%$. of trisodium citrate dihydrate as a green and sustainable catalyst in water under microwave irradiations (Table 3, entry 5). No significant yield of the desired product was observed upon increasing the catalyst loading upto $12 \mathrm{~mol} \%$ (Table 3 , entry 6).When the reaction was carried out in the absence of catalyst no product formation as takes place (Table 3, entry 11). Compound $4 \mathrm{a}$ was characterized by its physical and analytical data. The physical and analytical data were found to be comparable with the data reported in literature. All the results obtained are summarized in the table 4, and the comparative results of reported methods and our method are given in table 1 .

Table 1: Comparison of present methodolgy with reported methodology

\begin{tabular}{|c|l|c|c|c|}
\hline Entry & \multicolumn{1}{|c|}{ Catalyst } & Reaction Conditions & Yield (\%) & Reference \\
\hline 1 & Agar & EtOH, reflux, 25 min. & 94 & 12 \\
\hline 2 & Citric acid & Solvent-free, $80{ }^{\circ} \mathrm{C}, 7 \mathrm{~min}$ & 92 & 13 \\
\hline 3 & Fumaric acid & Solvent-free, $80{ }^{\circ} \mathrm{C}, 12 \mathrm{~min}$ & 93 & 15 \\
\hline 4 & L-valine & $\mathrm{H}_{2} \mathrm{O}, 70{ }^{\circ} \mathrm{C}, 2-3 \mathrm{~h}$ & 94 & 20 \\
\hline 5 & Multi-SO $\mathrm{S}_{3} \mathrm{H}$ functionalized ionic liquid & Solvent-free, 20 min. & 78 & 24 \\
\hline 6 & Ionic liquid (catalyst) & Solvent-free, $80{ }^{\circ} \mathrm{C}, 9$ min. & 86 & 25 \\
\hline 7 & Sphalerite & Solvent-free, $80{ }^{\circ} \mathrm{C}, 85$ min. & 93 & 29 \\
\hline 8 & Trichloroisocyanuric acid & Neat, $80{ }^{\circ} \mathrm{C}, 40 \mathrm{~min}$. & 97 & 31 \\
\hline 9 & Zinc oxide micelles & $\mathrm{H}_{2} \mathrm{O}, 90{ }^{\circ} \mathrm{C}, 8 \mathrm{~h}$ & 96 & 33 \\
\hline 10 & Trisodium citrate dihydrate & $\mathrm{H}_{2} \mathrm{O}, \mathrm{MW}, 10 \mathrm{~min}$ & 94 & This work \\
\hline
\end{tabular}

Table 2: Optimization of reaction solvents ${ }^{\mathrm{a}}$

\begin{tabular}{|c|c|c|c|}
\hline Entry & Solvents & Time & Yield (\%) \\
\hline 1 & Water & 10 & 92 \\
\hline 2 & Ethanol & 15 & 41 \\
\hline 3 & Methanol & 15 & 56 \\
\hline 4 & Acetonitrile & 10 & 43 \\
\hline 5 & DMF & 15 & 34 \\
\hline 6 & DMSO & 15 & 52 \\
\hline
\end{tabular}

${ }^{\mathrm{a}}$ Reaction conditions: $\beta$-Naphthol $(0.69 \mathrm{mmol})$, benzaldehyde $(0.83 \mathrm{mmol}), 2$-aminobenzothia-zole $(0.83 \mathrm{mmol})$, and catalyst $(10 \mathrm{~mol} \%)$ in $1 \mathrm{~mL} \mathrm{H}_{2} \mathrm{O}$, microwave irradiations, $10-15 \mathrm{~min}$.

${ }^{\mathrm{b}}$ Isolated yield. 
Table 3: Screening of reaction cataysts ${ }^{\mathrm{a}}$

\begin{tabular}{|c|l|c|c|}
\hline Entry & Catalysts & Time (min.) & Yield (\%) $^{\mathbf{b}}$ \\
\hline 1 & Trisodium citrate dihydrate $(2 \mathrm{~mol} \%)$ & 10 & 23 \\
\hline 2 & Trisodium citrate dihydrate $(4 \mathrm{~mol} \%)$ & 10 & 41 \\
\hline 3 & Trisodium citrate dihydrate $(6 \mathrm{~mol} \%)$ & 10 & 54 \\
\hline 4 & Trisodium citrate dihydrate $(8 \mathrm{~mol} \%)$ & 15 & 78 \\
\hline 5 & Trisodium citrate dihydrate $(10 \mathrm{~mol} \%)$ & 10 & 92 \\
\hline 6 & Trisodium citrate dihydrate $(12 \mathrm{~mol} \%)$ & 10 & 84 \\
\hline 7 & Sodium chloride $(10$ mol\%) & 15 & 31 \\
\hline 8 & Potassium bromide $(10$ mol\%) & 20 & 20 \\
\hline 9 & Triethyl amine $(10$ mol\%) & 20 & $\mathrm{nr}$ \\
\hline 10 & Tartaric acid $(10$ mol\%) & 20 & $\mathrm{nr}$ \\
\hline 11 & No Catalyst & $\mathrm{nr}$ \\
\hline
\end{tabular}

${ }^{a}$ Reaction conditions: $\beta$-Naphthol $(0.69 \mathrm{mmol})$, benzaldehyde $(0.83 \mathrm{mmol})$, 2-aminobenzothiazole $(0.83 \mathrm{mmol})$, and catalyst $(10 \mathrm{~mol} \%)$ in $1 \mathrm{~mL} \mathrm{H}{ }_{2} \mathrm{O}$, microwave irradiations, $10-20 \mathrm{~min}$.

b Isolated yield.

${ }^{\mathrm{c}}$ No reaction.

Further, to check the efficiency and feasibility of the reaction, we have carried out a number of reactions between 2-aminobenzothiazole, $\beta$-naphthol and variety of substituted aromatic aldehydes having electron-donating and electron-withdrawing groups in the aromatic ring such as $-\mathrm{CH}_{3},-\mathrm{OCH}_{3},-\mathrm{Cl},-\mathrm{OH},-\mathrm{F},-\mathrm{Br}$ and $-\mathrm{NO}_{2}$ using the optimized reaction conditions. All the reactions undergo smoothly under microwave irradiations but our methodology does not woks under ultrasonication and the desired product are obtained in very low yield ranging from $21-42 \%$ in $10 \mathrm{~min}$. It may be seen from the physicochemical data as shown in table 4 , that when electron with drawing group is present as substituent in reacting aldehydes, the yield of the product decreases, whereas electron donating group facilitates the reaction in forward direction as a result of which, yield of the product increases. Same results are obtained when the reaction is carried out at gram scale synthesis.

Table 4: Substrate scopefor 2-aminobenzothiazolomethyl naphthols ${ }^{\mathrm{a}}$

\begin{tabular}{|c|c|c|c|c|c|c|c|}
\hline \multirow{2}{*}{ Compound } & \multicolumn{2}{|c|}{ Time $^{b} /$ Yield $(\%)^{c}$} & \multirow{2}{*}{ M.P. $\left({ }^{\circ} \mathrm{C}\right)$} & \multirow{2}{*}{ Compound } & \multicolumn{2}{|c|}{ Time/Yield (\%) } & \multirow{2}{*}{ M.P. $\left({ }^{\circ} \mathbf{C}\right)$} \\
\hline & $\mathbf{U S I}^{\mathrm{d}}$ & $\mathbf{M W I}^{\mathbf{e}}$ & & & USI & MWI & \\
\hline & $10 / 23$ & $10 / 92$ & 202-204 & & $10 / 41$ & $10 / 94$ & 196-198 \\
\hline & $10 / 39$ & $10 / 94$ & $185-186$ & & $10 / 36$ & $10 / 94$ & 194-195 \\
\hline & $10 / 21$ & $10 / 91$ & 197-198 & & $10 / 28$ & $10 / 90$ & 189-190 \\
\hline & $10 / 23$ & $10 / 91$ & 191-192 & & $10 / 31$ & $10 / 91$ & 201-202 \\
\hline $4 c$ & & & & $4 \mathrm{k}$ & & & \\
\hline
\end{tabular}




\begin{tabular}{|l|l|l|l|l|l|l|}
\hline & & & & 10 & 174 \\
\hline
\end{tabular}

${ }^{\text {a }}$ Reaction conditions: $\beta$-Naphthol $(0.69 \mathrm{mmol})$, 2-aminobenzothiazole $(0.83 \mathrm{mmol})$, substituted aldehydes $(0.83 \mathrm{mmol})$, and trisodium citrate dihydrate $(10 \mathrm{~mol} \%)$ in $2 \mathrm{~mL}$ water, microwave irradiations for about $10 \mathrm{~min}$.

${ }^{\mathrm{b}}$ Time in minutes, ${ }^{\mathrm{c}}$ Isolated yield, ${ }^{\mathrm{d}}$ Ultrasonic Irradiations, ${ }^{\mathrm{e}}$ Microwave Irradiations.

All the desired products were obtained in pure form by washing with hot ethanol followed by recrystallization from hot ethyl acetate and hexane mixture; therefore, tedious column chromatography was not required. The isolated products were characterized by the study of physico-chemical data including IR, $\quad{ }^{1} \mathrm{H}-\mathrm{NMR},{ }^{13} \mathrm{C}$ NMR and mass spectra.

Moreover, the practicability and feasibility of the present method were tested by performing a model reaction on one gram scale. In this perspective, $\beta$ Naphthol $(6.9 \mathrm{mmol})$, benzaldehyde $(8.28 \mathrm{mmol})$ and 2aminobenzothiazole $(8.28 \mathrm{mmol})$, were reacted in the presence of trisodium citrate dihydrate catalyst (10 $\mathrm{mol} \%$ ) in $10 \mathrm{~mL}$ water under optimised reaction conditions to give2-aminobenzothiazolomethyl naphthols in about $10 \mathrm{~min}$. The reaction underwent smoothly affording the desired products 4ain $89 \%$ yield, which is almost similar with that of 0.069 mmol scale (table 2, entry 1), but required slightly more time for the completion.

Further more, a competitive experiment was performed for checking whether any change in the starting materials would cause variation in the yield of the product. In the experiment, $\beta$-naphthol 1 and 2aminobenzothiazole 3 were allowed to react with an equimolar mixture of 3-methoxybenzaldehyde and 3nitrobenzaldehyde 2 , products $4 \mathrm{~b}$ and $4 \mathrm{c}$ were obtained in $57 \%$ and $21 \%$ yields respectively. The experiment concluded that, when the reacting substrates having electron-donating and electron-withdrawing groups were allowed to react individually, they provided improved yields as compared to a substrates containing electronwithdrawing group. However, in the mixture, substrates having electron-donating group not only reacted faster, but also resulted in higher yields of the product as compared to substrates having electron-withdrawing group.

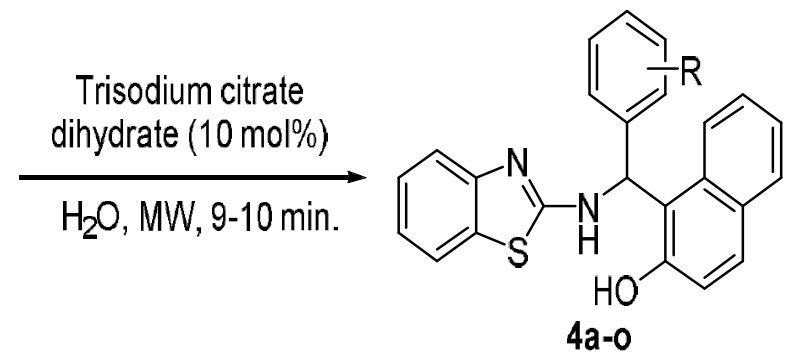

Scheme 1 Synthesis of 2-aminobenzothiazolomethyl naphthols 


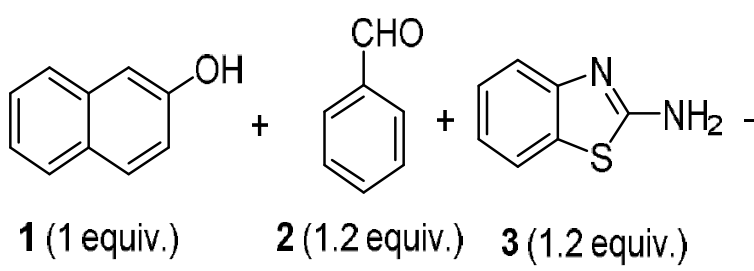

$\{1 \mathrm{~g}\}$<smiles>COc1ccc2ccccc2c1C(Nc1nc2ccccc2s1)c1ccccc1</smiles>

$\{1.57 \mathrm{~g}\}$

$89 \%$ yield

\section{Scheme 2 Gram scaled up synthesis of 2-aminobenzothiazolomethyl naphthols}

Next, we turned out our attention towards the green chemistry aspects of the developed protocol i.e. possibility of recyclability and reusability of the reaction media and catalyst. It is very noteworthy to note that, after completion of the reaction, we successfully reused the reaction media having residual starting materials, catalyst and solvent obtained upon filtration of the reaction mixture. The recovered reaction media of the reaction may be reused for model reaction (Table 5) for at least five additional times (except fresh cycle) in subsequent reaction without significant loss in product yields. The desired product $4 \mathrm{a}$ was isolated in $93-90 \%$ yields. The results are represented in table5. This is important to be noted that each filtrate may only be used for a particular entry due to presence of residual starting materials.<smiles>COc1cccc(C=O)c1</smiles><smiles>COc1cccc(C(Nc2nc3ccccc3s2)c2c(O)ccc3ccccc23)c1</smiles>

Scheme 3 Competitive experiment

Table 5: Reuse of reaction media for the reaction ${ }^{a}$

\begin{tabular}{|c|c|c|c|c|c|c|}
\hline No. of $_{\text {cycles }}{ }^{\text {a }}$ & Fresh & Cycle-1 & Cycle-2 & Cycle-3 & Cycle-4 & Cycle-5 $^{\text {Cyeld }}$ \\
\hline Yime (min.) $^{\mathbf{b}}$ & 93 & 93 & 92 & 92 & 90 & 90 \\
\hline Time & 10 & 10 & 10 & 10 & 10 \\
\hline
\end{tabular}

${ }^{a}$ Reaction condition: $\beta$-Naphthol $(0.69 \mathrm{mmol}), 2$-aminobenzothiazole $(0.83 \mathrm{mmol})$, benzaldehydes $(0.83 \mathrm{mmol})$, and trisodium citrate dihydrate $(10 \mathrm{~mol} \%)$ in $2 \mathrm{~mL}$ water under microwave irradiations for $10 \mathrm{~min}$.

${ }^{\mathrm{b}}$ Yields refer to pure isolated yields. 


\section{CONCLUSION}

In this study, we have developed a new trisodium citrate dihydrate catalyzed simple, efficient and practical one-flask method for the synthesis of 2aminobenzothiazolomethyl naphthols from, $\beta$-naphthol, substituted aromatic aldehydes and 2-aminobenzothiazole in water under microwave irradiations. The product formation takes shorter duration with good to excellent yield. Use of eco-friendly solvent, catalyst, mild reaction conditions, easy to workup, the absence of tedious separation process, wide substrate tolerance, reusability of the reaction media and gram scale synthetic applicability make the method more advantageous over reported procedures. Furthermore, the present method is readily controllable to large scale synthesis of pharmaceutically important molecule.

\section{REFERENCES}

Amnerkar N.D. and Bhusari K.P., 2010. Synthesis, anticonvulsant activity and 3D-QSAR study of some prop-2-eneamido and 1-acetyl-pyrazolin derivatives of aminobenzo-thiazole. Eur. J. Med. Chem., 45(1):149-159.

Adrom B., Maghsoodlou M.T., Hazeri N. and Lashkari M., 2015. Solvent-free synthesis of 1-(benzothiazolylamino)methyl-2-naphthols with maltose as green catalyst. Res. Chem. Intermed., 41(10): 7553-7560.

Brahmachari G. and Nurjamal K., 2019. Ultrasoundassisted and trisodium citrate dihydratecatalyzed green protocol for efficient and onepot synthesis of substituted chromeno[3', $\left.4^{\prime}: 5,6\right]$ pyrano-[3,2- $d]$ pyrimidines at ambient conditions. Tetrahedron Lett., 60:1904-1908.

Brahmachari G. and Banerjee B., 2016. Facile and chemically sustainable one-pot synthesis of a widearray of fused $O$-and $N$-heterocycles catalyzed by trisodiumcitrate dihydrate under ambient conditions. Asian. J. Org. Chem., 5:271286.

Brahmachari G. and Nurjamal K., 2016. Trisodium citrate dihydrate-catalyzed one-pot three-component synthesis of biologically relevant diversely substituted 2-amino-3-cyano-4-(3-indolyl)- $4 H$ chromenes under eco-friendly conditions. Current Green. Chem., 3:248-258.

Choi S.J., Park H.J., Lee S.K., Kim S.W., Han G. and Choo H.Y.P., 2006. Solid phase combinatorial synthesis of benzothiazoles and evaluation of topoisomerase II inhibitory activity. Bioorg. Med. Chem., 14(4):1229-1235.

Dömling A., Wang W. and Wang K., 2012. Chemistry and biology of multicomponent reactions. Chem. Rev., 112:3083-3135.

El-Shorbagi A.N., Sakai S.I., El-Gendy M.A., Omar N. and Farag H.H., $1989 . \quad$ Imidazo[2,1-b] benzothiazoles. II. Synthesis and antiinflammatory activity of some imidazo[2,1b] benzothiazoles. Chem. Pharm. Bull., 37(11):2971-2975.

Erian A.W., 1993. The chemistry of beta-enaminonitriles as versatile reagents in heterocyclic synthesis. Chem. Rev., 93:1991-2005.

Fardpour M., Safari A. and Javanshir S., 2018. $\gamma$ aminobutyric acid and collagen peptides as recyclable bifunctional biocatalysts for the solvent-free one-pot synthesis of 2-aminobenzothiazolomethyl-2-naphthols. Green Chem. Lett. Rev., 11(4):429-438.

Hutchinson I., Chua M-S., Browne H.L, Trapani V., Bradshaw T.D., Westwell A.D. and Stevens M.F.G., 2001. Antitumor benzothiazoles. 14. Synthesis and in vitro biological properties of fluorinated 2-(4-aminophenyl) benzothiazoles. J. Med. Chem., 44(9):1446-1455.

Hulme C., Chappeta S., Griffith C., Lee Y-S. and Dietrich J., 2009. An efficient solution phase synthesis of triazadibenzoazulenones: 'designer isonitrile free' methodology enabled by microwaves. Tetrahedron Lett., 50:1939-1942.

Hosseinian A. and Shaterian H.R., 2012. $\mathrm{NaHSO}_{4} \cdot \mathrm{H}_{2} \mathrm{O}$ catalyzed multicomponent synthesis of 1-(benzothiazolylamino) methyl-2-naphthols under solvent-free conditions. Phos. Sulfur Sil. Related Elements, 187:1056-1063.

Javanshir S., Ohanian A., Heravi M.M., Naimi-Jamal M.R. and Bamoharram F.F., 2014. Ultrasoundpromoted, rapid, green, one-pot synthesis of 2'aminobenzothiazolomethyl-naphthols via a multi-component reaction, catalyzed by heteropolyacid in aqueous media. J. Saudi Chem. Soc., 18:502-506.

Jiang B., Rajale T., Wever W., Tu S.J. and Li G., 2010. Multicomponent reactions for the synthesis of heterocycles. Chem. Asian J., 5:2318-2335. 
Kamali F. and Shirini F., 2018. $\mathrm{Fe}_{3} \mathrm{O}_{4} @ \mathrm{SiO}_{2}-\mathrm{ZrCl}_{2}-$ MNPs: A novel magnetic catalyst for the clean and efficient cascade synthesis of 1(benzothiazolylamino) methyl-2-naphthol derivatives in the absence of solvent. Appl. Organometal. Chem., 32(1):1-12.

Kumar A., Rao M.S. and Rao V.K., 2010. Sodium dodecyl sulfate-assisted synthesis of 1-(benzothiazolylamino) methyl-2-naphthols in water. Australian J. Chem., 63(11):1538-1540.

Lal J., Gupta S.K. and Agarwal D.D., 2012. Chitosan: An efficient biodegradable and recyclable green catalyst for one-pot synthesis of 3,4dihydropyrimidinones of curcumin in aqueous media. Catal. Commun., 27:38-43.

Lal J., Gupta S.K., Thavaselvam D. and Agarwal D.D., 2016. Synthesis, structure assignment and pharmacological evaluation of synthesized curcumin derivatives as antioxidant and antiinflammatory activity. Chinese Chem. Lett., 27:1067-1072.

Lashkari M., Maghsoodlou M.T., Karima M., Adrom B. and Fatahpour M., 2016. Convenient approach for the one-pot,three-component synthesis of1(benzothiazolylamino)methyl-2-naphthol using citric acid as a green catalyst. Acta. Chemica. Iasi, 24(2):112-121.

Lei Z-K., Xiao L., Lu X-Q., Huang H. and Liu C-J., 2013. Graphite-supported perchloric acid $\left(\mathrm{HClO}_{4}-\mathrm{C}\right)$ : An efficient and recyclable heterogeneous catalyst for the one-pot synthesis of amidoalkylnaphthols. Molecules, 18:1653-1659.

Lal J., Singh S. and Rani P; 2020. Synthesis of 2aminobenzothiazolomethyl naphthols using L-valine organocatalyst: An efficient, versatile and biodegradable catalyst. Chem. Africa, 3:53-60.

Lati M.P., Shirini F., Alinia-Asli M. and Rezvani M.A., 2018. Synthesis of 1-(benzothiazo-lylamino) phenylmethyl-2-naphthols accelerated by a novel magnetic nanocatalyst. J. Iran Chem. Soc., 15(7):1655-1662.

Li W-L., Wang L-L. and Luo Q-Y., 2013. One-pot synthesis of 2'-aminobenzothiazolo-arylmethyl2-naphthols catalyzed by NBS under solventfree conditions. The Sci. World J. 2013.
Lal J., 2015. Sphalerite: A natural catalyst for an efficient synthesis of 2-aminobenzothia-zolomethyl naphthol derivatives under solvent-free conditions. Intl. J. Inter. Res., 2(1):5-10.

Maghsoodlou M.T., Karima M., Lashkari M., Adrom B. and Hazeri N., 2016. Convenient approach for the one-pot, three-component synthesis of 1(benzothiazolylamino) methyl-2-naphthol using fumaric acid as a green catalyst. Bulgarian Chem.Commun., 48(3):369-272.

Moradi A.R., Heydari and Maghsoodlou M.T., 2015. Agar: A novel, efficient, and biodegradable catalyst for the one-pot three-component and green synthesis of 2,3-di-hydroquinazolin4(1H)-one, 4H-pyrimidobenzothiazole and 2aminobenzothiazolomethyl naphthol derivatives. Res. Chem. Intermediates, 41(10):7377-7391.

Mohan M.M., Santosh C.H. and Radhaiah A., 2015. A one-pot three component green synthesis of 1aminoalkyl-2-naphthols using grindstone chemistry. Int. J.Curr. Microbiol. App. Sci., 4(3):1000-1008.

Mou J., Gao G., Chen C., Liu J., Gao J., Liu Y. and Pei D., 2017. Highly efficient one-pot threecomponent Betti reaction in water using reverse zinc oxide micelles as a recoverable and reusable catalyst. RSC Adv., 7:13868-13875.

Niralwad K.S., Shingate B.B. and Shingare M.S., 2011. 1-Hexanesulphonic acid sodium salt promoted the one-pot synthesis of amidoalkylnaphthols under microwave-irradiation. Chinese Chem. Lett., 22:551-554.

Ohanian A., Javanshir S., Heravi M.M. and Bamoharram F.F., 2009. One-pot synthesis of 2'-aminobenzothiazolomethylnaphtols in water catalyzed by Wells-Dawson heteropoly acid. In: $13^{\text {th }}$ Intl. Elementary Conf. Synth. Org. Chem., pp.1-4.

Paget C.J., Kisner K., Stone R.L. and Delong D.C., 1969. Heterocyclic substituted ureas. I. Immunosuppression and virus inhibition by benzimidazoleureas. J. Med. Chem., 12:10101015.

Palkar M., Noolvi M., Sankangoud R., Maddi V., Gadad A. and Nargund L.V.G., 2010. Synthesis and antibacterial activity of a novel series of 2,3diaryl-substituted-imidazo(2,1-b)-benzothiazole derivatives. Arch der Pharm., 343(6):353-359. 
Shaabani A., Rahmati A. and Farhangi E., 2007. Water promoted one-pot synthesis of 2'-aminobenzothiazolomethyl naphthols and 5-(2'aminobenzothiazolomethyl)-6-hydroxyquinolines Tetrahedron Lett., 48:7291-7294.

Shaterian H.R. and Hosseinian A., 2014. Preparation of 1-(benzothiazolylamino)methyl-2-naphthols using multi- $\mathrm{SO}_{3} \mathrm{H}$ functionalized ionic liquid under solvent-free conditions. Scientia Iranica, 21(3):727-734.

Shaterian H.R. and Mohammadnia M., 2013. Acidic Brønsted ionic liquids catalyzed the preparation of 1-((benzo[ $d]$ thiazol-2-ylamino)(aryl)methyl)naphthalen-2-ol derivatives 1-[(1,3benzo-thiazol-2-ylamino)(aryl)methyl]-2naphthol. S. African J. Chem., 66:60-63.

Singh T., Srivastava V.K., Saxena K.K., Goel S.L. and Kumar A., 2006. Synthesis of new thiazolylthiazolidinylbenzothiazoles and thiazolylazetidinylbenzothiazoles as potential insecticidal, antifungal, and antibacterial agents. Arch der. Pharm., 339(8):466-472.

Yang L., 2012. Trichloroisocyanuric acid, a new and efficient catalyst for the synthesis of 2'aminobenzothiazoloarylmethyl-2-naphthols. EJournal Chem., 9(4):2424-2428.

Yu Y. and Guo H-Y., 2011. One-pot synthesis of 2'aminobenzothiazoloarylmethyl-2-naphthols in ionic liquid of $[\mathrm{Hnmp}] \mathrm{HSO}_{4}$ under solvent-free conditions. Chinese J. Org. Chem., 31(1):96-100.

Zimou O., Malek B., Elhallaoui A., Ghailane T., Ghailane R., Boukhris S., Habbadi N., Hassikou A. and Souizi A., 2019. Valorization of the phosphate fertilizers catalytic activity in 1-(benzothiazolylamino)methyl-2-naphthol derivatives synthesis. Bull. Chem. Reaction Engg. Catal., 14(2):238-246. 